\title{
ERGOGENIC EFFECTS OF CAFFEINE DOSE ON MAXIMAL AEROBIC POWER OF NORMAL NIGERIAN UNDERGRADUATE STUDENTS.
}

\author{
Journal website at; \\ http://mrtbjournal.org/index.php/njmr/issue/current/showToc \\ * Lamina Sikiru and ${ }^{+}$Musa Danladi Ibrahim \\ Faculty of Medical Sciences, Jimma University, Ethiopia, \& ${ }^{+}$Health Education Unit, \\ Department of Education Foundation, Benue State University, Makurdi, Nigeria. \\ Correspondence to: \\ Lamina Sikiru \\ E-mail: siklam_86@yahoo.co.uk \\ Tel. $+25 \overline{1} 917832824$
}

\section{SUMMARY}

Objective:- The objective of this study was to determine the effects of $5 \mathrm{mg} / \mathrm{kg}$ dose of caffeine on maximal aerobic power of normal male Nigerian adults.

Method:- Twenty normal male adults volunteers participated. A repeated measure 2 randomized crossover (counter balanced) double blind design was used in data collection. Subjects engaged in 20 meter shuttle run test (20 MST) one hour Post caffeine (5 ${\mathrm{mg} . \mathrm{kg}^{-}}^{1}$ ) and placebo doses ingestion. Endurance Performance indexes $\left(\mathrm{VO}_{2} \max\right.$, run time \& number of exercise laps) were recorded.

Result:- Repeated measures t-test was used to assess the level of significant difference between caffeine doses and placebo dose in $\mathrm{VO}_{2}$ max, run time and number of exercise laps. The result showed no significant effect of caffeine doses over placebo dose at $\mathrm{P}<0.05$.

Conclusion:- It was concluded that instant soluble coffee (Caffeine) dose of $5 \mathrm{mg} / \mathrm{kg}$ ( $300 \mathrm{mg}$ caffeine) seems not have any ergogenic effect on max aerobic power of normal Nigerian Adults.

Key words :Coffee, Caffeine, Exercise, ergogenic, VO2 max

\section{INTRODUCTION}

Caffeine (1,3,7-trimethyl-xanthine) is a methyl derivative of xanthine (Robertson et al, 1981; Van Handel, 1983). It is basically a Purina compound containing two condensed heterocyclic rings. It is a naturally occurring chemical found in over 60 different species of plant leaves, seeds and fruits. Specifically, caffeine is found in coffee (coffee Arabica), tea, cola nuts (cola acuminata). It is also found but in little quantity in cocoa (theobroma cacao) Essig et al, 1980; Van Handel 1983; Wilcox 1990).
The ability of caffeine and other xanthines to aid sport performance is based on the direct action on the heart or skeletal muscles or indirect actions on these organs, mediated through the nervous system, altered hormonal activities or shift in mobilization of substances (free fatty acid mobilization and glycogen sparing). There is also the possibility that the drug may alter the release, binding or activity of neurotransmitter in the brain, thereby affecting the perception of work intensity (Robertson et al., 1981).

The controversy surrounding the use of caffeine as food beverages by laymen or use as an ergogenic aid by local, national and international athletes has drawn the attention of many scientists to research into the effects of this drug. Some studies (Wilcox, 1990; Graham et al, 1994; Clark, 1997) view this aid as a justifiable extension of the body's natural capacities, while others (Jacobson and kulling, 1989; Engs ,1991; Spriet, 1995; Ahrendt, 2001) see it as a dangerous and unethical violation of the code of fair play in sports.

Due to the controversial reports of some studies (Perking and Williams ,1975; Costill, 1978; Costill, et al 1978; Ivy et al.,1979) on the ergogenic effect of caffeine on performance, the International Olympic Committee (IOC) had a series of banned, un-banned and finally pegged the use of caffeine in sports competition to a tolerance limit of 12 ug,ml- ${ }^{-}$urine (Wilcox,1990; Devries \& Housh, 1994; Pasma et al., 1995). Pasma, et al. (1995), kovacs, et al (1998) and Bruce, et al. (2000) reported that the doses below $6 \mathrm{mg} . \mathrm{kg}^{-}{ }^{1}$ caffeine do not exceed the IOC urinary caffeine limit. However, in 2004 and to date, the World Anti Doping Agency (WADA) completely removed caffeine from the list of banned substances (WADA 2003; 2004; 2005; 2006; 2007).

However, previous studies on the ergogenic effect of caffeine has been equivocal, mostly laboratory oriented and on white or other non African black subjects. Hence, 
the present study was therefore designed to investigate the ergogenic effect of varied doses of caffeine on black Africans (Nigerian subjects) using maximal aerobic field test (20 meter shuttle run test).

\section{MATERIALSAND METHODS}

Subjects:- Twenty (20) male subjects of Bayero University Nigeria aged between $18-25$ years participated. They were non athletes, non regular users of caffeine, non smokers and apparently healthy. Subjects were fully informed about the experimental procedure, risk and protocol. Subjects gave informed consent in accordance with the American College of Sports Medicine guidelines, regarding the use of human subjects (ACSM,1991). Also, the ethical approval of the Bayero University, was given through the Ethical Committee. The subjects' physical (weight and height) characteristics were measured and recorded using standardized anthropometric protocol (International Society for the Advancement of Anthropometry, 2001).

Design of the study: - Post-test placebo controlled design in which each subject served as his own control was used. It is a double blind 2 randomized counter balanced cross over order. The ingestion of $5 \mathrm{mg} . \mathrm{kg}^{-1}$ of caffeine and placebo, coupled with exercise was separated by seven days' interval to avoid carry over effect of caffeine and exercise (Graham, et al. 2000; Anderson, et al. 2000).

Physiological measurement:- Subjects SBP, DBP and HR were monitored on the right arm as described by walker et al (1992) Using semi-automated BP monitor (Omron digital BP monitor model 11 EM-403c, Tokyo Japan). The measurement was done in the morning between 9am and 10 am each test day.

Caffeine and placebo measurement:- The quantity of coffee to give the desired amount of caffeine needed ( 5 mg.km- ${ }^{-1}$ ) was measured using electronic weighing machine (Sartorous GMBH by Cottingen Germany). According to Eteng et al (1999), every $10.68 \mathrm{mg}$ coffee (Capra Nescafe coffee) commonly found in Nigeria contains $1 \mathrm{mg}$ caffeine, therefore $5 \mathrm{mg}$ caffeine amounted to $53.4 \mathrm{mg}$ coffee. Since pure caffeine is not readily available, Capra Nescafe coffee by Capra Nestle Company Abidjan, Cote De Voire was used. It is $100 \%$ pure instant soluble coffee. $0.1 \mathrm{ml}$ liquid food colour (coffee colour) by Ransons Exports, Faridaba Haryana India was used as Placebo. Both coffee doses and placebo were dissolved in $200 \mathrm{ml}$ warm water (Camba, 2001 ) and sweetened with artificial sweetner (Sweetexsaccharin by Crooks Healthcare Notingham) as described by Engels et al (1992).

Test Procedure:- The test was conducted between 8 am and $10 \mathrm{am}$; on arrival to the field (Bayero University Sports Complex) and following 10 minutes' rest in sitting position. Subjects SBP, DBP and HP were measured. Immediately subjects randomly ingested caffeine dose and placebo, subjects remain in sitting position for an hour (60 minutes). According to Robertson et al (1981) caffeine peak plasma concentration are reached at approximately 60 minutes regardless of the dose. Immediately after 60 minutes of the post caffeine ingestion, subjects warmed up for about 5minutes (easy jogging and stretching exercise) and got ready for the $20 \mathrm{MST}$.

The 20 MST was conducted on a leveled 20 metre marked course with chalk at each end. The test was performed in accordance with one minute protocol by Léger and Gadoury (1989) using the Progressive Aerobic Cardiovascular Endurance Run (PACER) tape. The tape gave a 5 second count down $(5,4,3,2,1)$ and instructed subjects to "begin".

About 10 subjects lined up behind the starting line. A partner was assigned to each subject to count the number of laps completed (a lag consisted of 20 meter distance). A the command "start"!, subjects ran in a straight line forth and back between restraining lines in accordance with the pace dictated by the audio signal emitted at a set intervals from the PACER tape. Subjects continued in this manner until they were unable to catch up with the sound of the beep for two consecutive times after which the test was terminated. The number of laps and time completed by each subject was recorded as his predicted cardiorespratory fitness score using the formula of Reunsbottom, et al, (1988) as follows: $\mathrm{VO}_{2} \max =14.4+3.48$ (minute completed).

The total test duration was 2 weeks ([once weekly] to avoid carry over effect) in a 2 randomized (5 mg.kg-' and placebo) crossover counterbalanced manner.

\section{Statistical analysis}

Following data collection, the variables of interest were statistically analyzed. Mean and Standard Deviation were determined for all variables. Caffeine dose (5 mg.kg') and placebo dose exercise performance ( $\mathrm{VO}_{2} \max$, run time, and no of laps) were statistically analyzed using repeated measured t-test. All statistical analysis was performed on an IBM compatible micro computer using the Statistical Package for the Social Science (SPSS), Chicago IL USA). The probability level for all the above tests was set at 0.05 to indicate significance.

\section{RESULTS}

Twenty males participated in this study, subjects mean (SD) age, resting SBP, DBP and HR and were 22.3 (4.0) years, $127(5.4) \mathrm{mmHg}$, 78(4.2) $\mathrm{mmHg}$ and 70(4.8) beats/ minute respectively. Their physical characteristics are presented in table 1. Mean quantity of coffee and equivalent caffeine ingested was $3198.66 \mathrm{mg}$ and 299.50 respectively; while placebo was coffee/caffeine free.

Table 2 shows no significant effect of caffcine doses $(5 \mathrm{mg} / \mathrm{kg})$ over placebo on the number of exercise laps $(\mathrm{t}[20]=2.08, \mathrm{p}=0.750)$; run time $(\mathrm{t}[20]=2.08, \mathrm{p}=0.760)$ and $\mathrm{VO}_{2} \max (\mathrm{t}[20], \mathrm{p}=0.801)$. 
Table 1: Physical characteristics of subjects $(\mathrm{N}=\mathbf{2 0})$

\begin{tabular}{llll}
\hline Variables & Mean & S D & Range \\
\hline Age $($ years $)$ & 22.3 & 4.0 & $18.0-25.0$ \\
Height $(\mathrm{cm})$ & 169.3 & 5.4 & $160.0-180.0$ \\
Weight $(\mathrm{kg})$ & 59.3 & 5.5 & $52.0-73.0$ \\
Body mass index $\left(\mathrm{kg} \cdot \mathrm{m}^{-2}\right)$ & 21.0 & 4.6 & $20.3-22.5$ \\
Resting SBP $(\mathrm{mm} \mathrm{Hg})$ & 127.0 & 5.4 & $120.0-130.0$ \\
Resting DBP $(\mathrm{m} \mathrm{mHg})$ & 78.0 & 4.2 & $72.0-80.0$ \\
Resting HR $(\mathrm{b} / \mathrm{min})$ & 70.0 & 4.8 & $68.0-78.0$ \\
\hline
\end{tabular}

Table 2: Exercise performance responses to caffeine (t-test)

\begin{tabular}{llll}
\hline Variables & Mean & S D & t-value \\
\hline No of laps (meters) & 72.8 & 2.7 & .688 \\
Run time (minutes) & 9.0 & 4.8 & .720 \\
$\mathrm{VO}_{2} \max$ (ml.kg-'.min-') & 42.0 & 4.6 & .864 \\
\hline
\end{tabular}

$\mathrm{t}(20)=2.086 \quad$ Not significant, $\mathrm{p}<0.05$

\section{DISCUSSION}

The purpose of the present study was to determine the effect of $5 \mathrm{mg} \cdot \mathrm{kg}_{-}{ }^{1}$ dose of caffeine on maximal aerobic power of normal Nigerian undergraduate students. The study result showed no significant effect of caffeine doses over placebo dose on maximal aerobic power $\left(\mathrm{VO}_{2} \max \right)$, run time and number of exercise laps.

The non ergogenic effect of caffeine as reposted in the present study is in agreement with previous studies (Engels and Haymes, 1992: Anderson and Hickey, 1994; Tunagol et al 1998; Herman and Young 1998). However, more recent studies (Arderson et al. 2000; Bruce et al, 2000; French et al, 2000) reported a contrary notion, that caffeine has ergogenic effect on endurance performance.

The study that was inconsistent with the present study was conducted by Mercola (2002) in which twenty one subjects ( 13 caffeine users and 8 non users) completed six randomized exercise ride to exhaustion at $80 \% \mathrm{VO}_{2} \max$ once per week following ingestion of $5 \mathrm{mg} . \mathrm{kg}^{\mathrm{i}} \mathrm{caffeine}$ and placebo. The ingestion of caffeine and placebo was preceded by exercise in one, three, and six hours. The study recorded significant effect of Caffeine over placebo in one and three hour and the effect was great in magnitude and lasting (duration) longer in non users.

Graham and Spriet (1995) examined the effect of different doses ( $3 \& 6 \mathrm{mg} \mathrm{kg}^{-}$) of caffeine and placebo on endurance exercise at $85 \% \quad \mathrm{Vo}_{2} \max$ run to voluntary exhaustion. They reported significant effect of all doses over placebo on endurance run time. Graham and Spriet (1991), Anderson et al (2000), and Frencb et al (2000) examined the effect of different caffeine $6 \mathrm{mg} . \mathrm{kg}^{-1}$. All the studies reported ergogenic effect of caffeine on trained athletes in a laboratory setting.

Bridge and Jones (2006) investigated the effect of a lower dose $(3 \mathrm{mg} / \mathrm{kg})$ of caffeine and placebo. Eight distance runner ingested caffeine and placebo, subjects ran $8 \mathrm{~km}$ race I hour post caffeine and placebo ingestion. Significant effect of caffeine was reported on enhancement of performance in an ecological valid race setting. Wiles et al (2006) also reported a similar result. Eight trained cyclist performed a $1 \mathrm{~km}$ time trial on electronically braked cycle ergometer following the ingestion of $5 \mathrm{mg} / \mathrm{kg}$ caffeine. They concluded that caffeine has ergogenic effect on short duration, high intensity exercise.

Another study that was inconsistent with the present study was conducted by Stuart et al (2005). Nine competitive rugby players ingested caffeine $(6 \mathrm{mg} / \mathrm{kg})$ dose and placebo. Subjects performed 2 straight and 3 agility sprints. They reported significant effect of Caffeine over placebo. Similar study was conducted by Schneider et al (2006). In their study, they examined the effect of similar dose $(6 \mathrm{mg} / \mathrm{kg})$ of caffeine and placebo on endurance exercise at $35 \%$ VO 2 max nun to voluntary exhaustion. They reported significant effect of caffeine dose over placebo in prolonged and intermittent sprint ability.

The reason for the inability of the present study to achieve any significant effect of caffeine doses over placebo dose and the disparity in finding between the present study and several other previous studies might not be unconnected to the fact that there may exist interracial, genetics and environmental differences in caffeine pharmacodynamic and pharmacokinetics (caffeine metabolism and tolerance) (Clerk 1997: Gamba, 2001;Grant and Ellis, 1986).

Most of the previous studies involved white or non African black subjects compared to the present study that utilized black African (Nigerian) subjects. Also, the effect of the type of caffeine and placebo used might not be rulled out.

According to Marquis, (1997) better coffees are lower in acid, higher in Caffeine and have longer lasting effect and that ground coffees are generally preferred to canred or instant soluble coffee. According to Burke and Biejen (2000), coffee also contains several other substances that may exert cardiovascular effects such as estrogen, nicotinic and phenols. Also, the effect of the type of placebo used might be another important factor, most of the previous studies used decaffeinated coffee as placebo. Burke and Biejen (2000) stated that various decaffeinated coffee vary considerably in chemical process used to reduce their caffeine content, this could affect caffeine tolerance, metabolism and performance. Also failure to distinguish between pure coffee and pure caffeine is also worth considering.

The effect of different types of exercise utilized vis-à-vis, mode, intensity and duration, separately or in combination with caffeine worth consideration. Most of the previous studies utilize laboratory oriented performance compared to field test (20 MST) in the present study. The psychological effect of motivation and competition mimicry nature of the field test that may mask the ergogenic effect of caffeine might not be rulled out. The effect of environmental factor on caffeine metabolism and tolerance are also worth consideration 


\section{CONCLUSION}

Based on the result of the present study, it was concluded that instant soluble coffee by Capra nestle of about $3199 \mathrm{mg}$ ( $300 \mathrm{mg}$ caffeine) which is equivalent to 5 mg kg-1 body weight, constitute no ergogenic effect on subjects of black A frican (Nigerian ) origin.

\section{REFERENCES}

- American College of Sports Medicine (1991) Policy statement regarding the use of human subjects and in formed consent. Medicine and Science in Sports and Excurse 16,467.

- Anderson MC, Bruce CR, Frase SF, Stepto NK, Klein R, Hopkins WJ. (2000) Improved 200 metre rowing performance in competitive oarswoman after caffeine ingestion.International Journal of Sports Nutitopn. 10(4): 646-675.

- Anderson, D . E and Hickey, M.S (1994) Effect of caffeine on the metabolic and cathecolamine responses to exercise in $5^{\circ}$ and $28^{\circ}$ Medicine and Science in Sports and Exercise 26(4): 453-456.

- Anhrendt, D.M (2001) Erogenic aid. councelling the athlete American Family Physician.63(5): 913-22.

- Bridge CA, Jones MA. The effect of caffeine ingestion on $8 \mathrm{~km}$ run performance in a field setting. $J$ Sports Sci. 2006 (24): 433-9

- Bruce C.R (2000) Enhancement of 2000-M rowing performance after caffeine ingestion. Medicine and Science in Sports and Exercise, 32(11): 1958-63

- Burke, V and Biejen, L.J (2000) Coffee, caffeine and blood pressure. Cardiovascular Rounds and Review. 4,187-197

- Clark, W (1997)Caffeire a users guide. The Physician and Sports Medicine,25(11).

- Costil,1 F.L (1978) Performance secrets. Runner' World $13,50-55$

- Costill, D.L; Dalskj G.P, and Fink, W.J. (1978) Effects of caffeine ingestion on metabolic and exercise performance. Medicine and Science in Sports and Exercise. 10:155-158

- Devries,H.D and Housh, T.T (1994) Physlogy of execise for physical education, athletics and exercise science. $\left(5^{\text {th }}\right.$ ed)Madison. WCB Brown and Benchmark publishers.

- Engel HJ, Wirth JC, Celik S, Dorsey JL. (1999)Infeluence of caffeine on metabolic and cardiovascular function during sustained light intensity cycling and at rest.Internatronal Journal of Sports Nutrition, 9(4): $361-70$

- Engels, H.J and Haymes, E.M (1992) Effect of caffeine ingestion on metabolic responses to prolonged waking in sedentary males. Internat ronal Journal of Sports Nutrition, 2: $386-396$

- Essig, D; Costill, D.L and VanHandel, P.J (1980) Effect of caffeine ingestion on utilization of muscle glycogen and lipid during leg ergometer cycling. International Journal of Sports Medicine.1: 86-90

- Eteng M.R, Eyong EU, Eka OU, Umoh IB, Ebong PE, Ettarh RR. (1999) Nigeria Nescafe coffee. Plant Food for Human Nutrition. 54(4): $337-344$

- Engs,R.C (1991) Resurgence of a new " clean living" movement in the united states Journal of School Health, 61: 155-159

3 French C, McNaughton L, Davies P, Tristram S (2000)Caffeine ingestion during exercise to exhaustion in elite distance runners. Medicine and Science in Sports and Exercise, 30,1958-64
- Gamba. A.A (2001)Effect of Caffeine ingestion on the P.P and R.R intervals of adult males. Journal of Health Physical Education Sports and Leisure Students, 2 (2): 17-24

- Grahan, TE, Heldge JW, Maclean BK, Kiens B, Richter EA. (2000) Caffeine ingestion does not alter carbohydrate or fat metabolism in human skeletal muscle during exercise. The Journal of Physiology, 529(3): 837-847 .

- Grahan T.E; Rush, J.W. \& Vansoeren M.H (1994) Caffeine and exercise mutualism and performace. Canadian Journal of Applied Physiology 19(2): 111-138

- Graham T.E \& Spriet L.L. (1991) performance and metabolic responses to high caffeine dose during prolonged exerase Journal of Applied physiology, 71(6): 2292-8.

- Graham, T.E \& Spriet, L.L(1995)Metabolic, catecholamine and exercise performance responses to various doses of caffeine. Journal of Physiology,78(3): 867-874.

- Grant,J.A \& Ellis, E.F (1986)Symposium update on theophyline. J. Allergy Cli Immunol. 78: 669 - 824.

- Herman, J.A \& Young, J.C (1998)Effect of caffeine on high intensity intermittent exercise to exhaustion. Medicine and Scence in Sports and Exercise, 30 (suppls) 5243.

- International Society for the Advancement of kinanthropometry (2001) Iinternational standards for anthropometric assessment. Potchefstroom, South Africa: Author

- lvy JL, Costil DL, Fink WJ.(1979)Influence of caffeine and carbohydrate feedings in endurance performance. Medicine and Science in Sports and Exercise.

- Jacobson, B.H \& Kulling, F.A (1989) Health and erogenic effects of caffeine. British Journal of Sports Medicine 23(1): $34-40$

- Kovacs EM, Stegen JH, Brouns F. (1998) Effect of caffeine drinks on substrate metabolism, caffeine excretion and performance. Journal of Applied physiology 85(2): 708-715

- Ledger, 1 \& Gadoury, C (1989)Validity of the 20 metre shuttle run test with one minute stages to predict $\mathrm{Vo}_{2}$ max in adults. Canadan Journal of Sports Science, 14(1): 21-26

- Marquis, T (1979). Effect of caffeine on performance. Unpublished Manuscript, University of Florida

- Mercola, J (2002) Exercise endurance 1,3 \&6 hour after ingestion in caffeine users and non users. Journal of Applied Physiology, 93(4): 12-14

- Perkins R \& William M.H (1975) Effect of Caffeine upon maximal muscular endurance of female. Medicine and Science in Sports and Exercise 7: 221-224

- Pasma WJ, VanBaak MA, Jeukendrup AE, DeHaan A (1995). The effect of different dosages of Caffeine on endurance performance time. International Journal of Sports Medicine, 16(4): 225-230

- Reunsbottom R, Brewer J \& Williams C, (1998) A progressive shuttle run test to estimate maximal oxygen uptake. British Journal of Sports Medicine 22(4): 141-144

- Robertson D, Wade D, Workman R, Woosley RL, Oates JA (1981) Tolerance of the humoral and homodynamic effects of caffeine in man Journal of Clinical Investigation. 64,11111117

- Schneiker,KT; Bishop, D; Dawson, B;Hacket, LP;(2006)E ffects of caffeine on prolonged intermittent - sprint ability in team sport athletes.Med Sci Sport Exerc 38(3): 578 - 85

- Stuart GR, Hopkins WG, Cook C, Cairs SP(2005).Multiple effects of caffeine on simulated high intensity team- sport performance. Med Sci Sport Exerc.; 37(11): 1998 - 2005

- Turnagol HH, Guner R, Bayer C, Cetemen M, Acikada C. 
(1998). The influence of coffee on incremental exercise recovery and post exercise urine caffeine, metabolites concentrations. Medicine and Science in Sports and Exercise.

- Van Handel, P(1983).Caffeine .In: M.H Williams (ed) Ergogenic aids in sports. Champaign. Human kinetics Publishers (pp 128-163).

- Walker AJ, Bassett DR, Duey WJ, Howley ET,Bond V, Torok DJ. (1992) Cardiovascular and plasma catecholamine responses to exercise in blacks and with. Hypertension, 20(4): $542-548$

- Wiles JD, Coleman D, Tegerdine M, Swaine IL.The effects of caffeine ingestion on performance time,speed and power during a laboratory based $1 \mathrm{~km}$ cycling time-trial. J Sports Sc. $2006 ; 249(11): 1$ I $65-71$

- Wilcox A.R (1990) Caffeine and endurance performance sports Nutrition (3)26. 